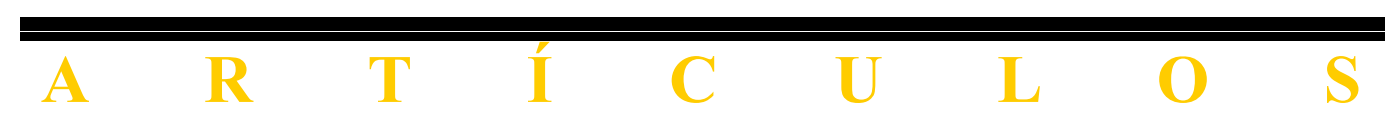




\section{PRIVACIDAD Y PUBLICIDAD}

0

Dos ancianos libidinosos se esconden entre los árboles de un parque y observan a una bella joven mientras se baña. Violan su intimidad, intentan seducirla y, al no lograrlo, la calumnian acusándola de adúltera. Sólo la intervención de un niño salva a la joven de la muerte. La joven se llama Susana y el niño Daniel. ${ }^{1}$ Lucas Cranach (el Viejo), Rembrandt y Berni se inspiraron en esta escena de espionaje privado, para deleite de los amantes del arte.

ii) Un cazador sorprende desnuda a una diosa mientras se baña en una fuente del bosque. Ovidio nos cuenta su historia: «El mismo color de que suelen teñirse las nubes cuando reflejan los rayos del sol, el mismo color que tiene la rosada Aurora, fue el que encubrió el rostro de la diosa al ser vista sin sus ropas; [...] le dijo en venganza estas palabras [...]: "Y ahora ve a contar por ahí que me has visto sin velos, si puedes."2 Por supuesto que no pudo: la diosa indignada transformó al cazador en un ciervo que muere devorado por sus propios perros.» Ovidio agrega: «Los comentarios son discordes: algunos piensan que la diosa fue más cruel de lo necesario, mientras que otros la elogian y consideran que actuó de acuerdo con su estricta castidad; unos y otros aducen sus razones. $\rangle^{3}$ La diosa se llama Diana y el cazador Acteón. Dos artistas del siglo XVII, Carlo Maratti y Gaspar Dughet, inmortalizaron pictóricamente la leyenda.

iii) A comienzos de 1973 dos médicos de reconocida fama llegaron a la conclusión clínica de que el candidato presidencial padecía arteriosclerosis y pericarditis. Si asumía el gobierno, no viviría más de un año. De este hecho estaba informado también otro posible candidato. Los tres personajes resolvieron respetar la intimidad del líder y no hacer pública esta noticia. El

\footnotetext{
${ }^{1}$ Libro de Daniel, 13.

${ }^{2}$ Ovidio, Metamorfosis, Madrid: Espasa 1994, págs. 143 s.

${ }^{3}$ Ibídem, pág. 146.
} 
$61,85 \%$ de los votantes lo eligió presidente el 23 de septiembre de 1973; el elegido no quiso falsear los pronósticos médicos y murió el $1^{\circ}$ de julio de 1974. Su esposa asumió la presidencia y este hecho fue uno de los factores desencadenantes de la mayor tragedia de la historia argentina. Los protagonistas de esta historia son los doctores Jorge Taiana y Pedro Cossio, Héctor Cámpora, Juan e Isabel Perón. ${ }^{4}$ El testimonio fotográfico de estos hechos forma parte de la documentación de una política demencialmente criminal. Los argentinos tuvieron menos suerte que los franceses que reeligieron en 1988 a un candidato enfermo de cáncer de próstata, ya en 1982. Sólo en 1994 la opinión pública tuvo conocimiento de este «secreto de Estado».

iv) En una inolvidable película, uno de los protagonistas, para paliar su aburrimiento de paralítico temporario y hacer más llevadera la ausencia de su insuperablemente encantadora novia, se dedica a espiar a sus vecinos con un catalejo. Logra así descubrir al culpable de un uxoricidio. Posiblemente todos hemos visto Rear Window (cuyo título en castellano, «La ventana indiscreta», es más elocuente para nuestro tema), y recordamos a James Stewart y a Grace Kelly.

v) El 15 de mayo de 1998, una esposa agraviada declara ante el juez penal que su marido le habría dicho que el autor intelectual del asesinato de un conocido periodista era un temido capomafia. Éste puso poco después fin a su vida y la justicia parece haber avanzado substancialmente en el esclarecimiento de este crimen. Los personajes de este reparto son Silvia Belawsky, su marido Gustavo Prellezo, el juez José Luis Macchi, el periodista José Luis Cabezas y el multimillonario Alfredo Yabrán.

vi) Una de las más lucrativas actividades del periodismo fotográfico es la practicada por los paparazzi, diligentes emuladores tecnificados de los ancianos bíblicos de Babilonia. No sólo la familia real inglesa sino figuras menos espectaculares de la vida política y social adornan con sus sorprendidas desnudeces y escenas de la vida privada las revistas del corazón desde Rovaniemi hasta Sidney y desde Tokio hasta Lima.

vii) El presidente de los Estados Unidos es sometido a observación permanente de su comportamiento sexual extramatrimonial y denunciado públicamente por supuestas hazañas de las que se ha tenido conocimiento a través de grabaciones telefónicas. Gennifer Flowers, Kathleen Willy, Paula Jones y Monica Lewinsky fueron catapultadas al centro de la opinión pública, no sólo americana, como víctimas de la supuestamente incontrolada pasión erótica de Bill Clinton.

viii) En marzo de 1998, la Sala H de la Cámara Nacional de Apelaciones en lo Civil (Buenos Aires) condenó a la revista argentina Noticias a pagar

\footnotetext{
${ }^{4}$ Cfr. Miguel Bonasso, El presidente que no fue. Los archivos secretos del peronismo. Buenos Aires: Planeta 1997, pág. 557.
} 
150.000 pesos al presidente Menem por haber violado su «derecho a la intimidad» publicando fotos e informaciones sobre su hijo extramatrimonial concebido con Martha Meza. La revelación de paternidad presidencial hizo recordar a algunos las informaciones publicadas el 10 de noviembre de 1994 por Paris Match acerca de la hija extramatrimonial de François Mitterrand. ${ }^{5}$

ix) Winston Smith vive en un país donde existe un tipo delictivo penado con la muerte o veinticinco años de trabajo forzado: el crimen de pensamiento (Thoughtcrime). Una policía de eficacia insuperable, la Thought-police, se encarga de la investigación de este delito: «El crimen de pensamiento no era algo que pudiera ser ocultado para siempre. Uno podía disimularlo por un tiempo, quizás durante años, pero tarde o temprano te hacían comparecer.» ${ }^{6}$

En todos estos casos existe, o se alega, una violación de la esfera privada de acuerdo con las pautas sociales imperantes en cada circunstancia. Pero, en el caso de Susana, al espionaje se suma la calumnia; en el de Diana, es la mirada curiosa la que ofende y el riesgo de la chismografía de un Acteón locuaz lo que provoca la venganza; James Stewart y Silvia Belawsky contribuyen a aclarar un crimen; las medidas que se adoptan en aras del respeto a la vida privada de los candidatos presidenciales presentan algunos rasgos que permitirían incluir estos casos en la categoría del engaño político, ese vicio de los gobernantes que tanto molestaba al marqués de Condorcet ${ }^{7}$; las desnudeces de Sara Ferguson no son las de una diosa y ella tampoco parece que quisiera actuar como Diana (en todo caso no como la de Ovidio); las aventuras del Salón Oval (o como quiera llamárselo) son más bien irrelevantes para la conducción política del país más poderoso del mundo; en el caso de la revista Noticias lo relevante para la opinión pública era también el hecho de que la madre de este hijo del presidente ocupaba una banca como diputada del partido del padre; en la pesadilla utópica (¿realmente utópica?) de George Orwell, ni siquiera los más íntimos pensamientos escapan al conocimiento del Big Brother. Y, sin embargo, ¿hay algo común a todos ellos que nos permita condenarlos moralmente? ¿Cuáles son los límites morales de la privacidad? O, dicho con otras palabras, ¿cuál es la relevancia moral de la privacidad?

En lo que sigue quiero analizar más de cerca estas cuestiones desde la posición de un demócrata liberal sensatamente tolerante y, por lo tanto, no

\footnotetext{
${ }^{5}$ Cfr. Clarín, Buenos Aires, 27 de marzo de 1998, pág. 42.

${ }^{6}$ Georg Orweil, Nineteen Eighty-Four, Londres: Penguin 1990, pág. 21.

${ }^{7}$ Cfr. Marie-Jean-Antoine-Nicolas de Caritat, Marqués de Condorcet, «Disertación filosófica y política o reflexión sobre esta cuestión: ¿Es útil para los hombres ser engañados?» en Javier de Lucas (ed.), ¿Es conveniente engañar al pueblo?, Madrid: Centro de Estudios Constitucionales 1991, págs. 183-219, pág. 216.
} 
relativista ni en el sentido de un Julius Ayer, con sus exclamaciones de aprobación o rechazo, ni en el de un Jean François Lyotard, dispuesto a aceptar que cada cual juegue su juego, cualquiera que éste sea.

Por lo pronto, conviene introducir algunas propuestas de precisiones conceptuales. Creo que conviene distinguir entre lo íntimo, lo privado y lo público.

La intimidad es el ámbito de los pensamientos de cada cual, de la formación de decisiones, de las dudas que escapan a una clara formulación, de lo reprimido, de lo aún no expresado y que quizás nunca lo será; es, no pocas veces, el marasmo que tanto suele interesar a los psicoanalistas desde que Freud les enseñara a distinguir entre el ello, el ego y el superego. ${ }^{8}$ Ya Thomas Hobbes lo sabía:

«Los pensamientos íntimos de una persona discurren sobre todo tipo de cosas -sagradas, profanas, puras, obscenas, graves y triviales- sin vergüenza o censura; lo cual no puede hacerse con el discurso verbal más allá de lo que sea aprobado por el juicio según el tiempo, el lugar y las personas. Un anatomista o un médico pueden expresar verbalmente o por escrito su opinión sobre cosas impuras porque no lo hacen para agradar sino para recibir sus emolumentos; pero que otra persona escriba sus fantasías extravagantes y placenteras sobre esto mismo sería como si alguien después de haber caído en el lodo viniera a presentarse ante un grupo de personas distinguidas. Y esta falta de discreción es lo que marca la diferencia.» ${ }^{9}$

Pero también parece que lo saben los esquimales:

«[...] guardan celosamente sus pensamientos sobre los demás y se niegan a responder preguntas personales.» ${ }^{10}$

El velo protector de la intimidad puede ser llamado, siguiendo a Hobbes, discreción. Se trata aquí de un velo de total opacidad que sólo podría ser levantado por el individuo mismo. Y de hecho así suele suceder: la entrega en el amor o el cultivo de una profunda amistad parece consistir en reducir al máximo la opacidad de nuestra intimidad. Lo que mortificaba a Winston Smith era precisamente la certidumbre de que sus pensamientos podían ser descubiertos por la Thought-police.

El ámbito de la intimidad escaparía a toda valoración moral si es que la moral ha de ser entendida como el conjunto de reglas que gobiernan relaciones

${ }^{8}$ Agradezco a Francisco Laporta el haberrne recordado la interpretación freudiana de la personalidad.

${ }^{9}$ Thomas Hobbes, Leviathan, Londres: J. M. Dent \& Sons Ltd. 1957, pág. 34. Citado según la versión castellana de Carlos Mellizo: Leviatán, Madrid: Alianza 1996, pág. 66.

${ }^{10}$ Avishai Margalit, The Decent Society, Cambridge, Mass.: Harvard University Press 1998, pág. 203. 
interpersonales y no se acepta una relación entre el hombre y un ser supraempírico como Dios. Es claro que en este último caso también los «malos pensamientos» pueden ser objeto de censura moral. Pero no es ello lo que ahora nos interesa.

La privacidad es el ámbito donde imperan exclusivamente los deseos y preferencias individuales. Es condición necesaria del ejercicio de la libertad individual. Parafraseando a Amartya Sen, podría decirse que la privacidad es la «esfera personal reconocida» que tendría que aceptar también todo liberal como punto de partida para la adopción de decisiones sociales que respondan a los ideales del liberalismo. Hasta qué punto esto puede conducir a la llamada «paradoja del liberal paretiano» es algo que puede ser dejado aquí de lado. ${ }^{11}$

Pero, no es necesario ser liberal para aceptar la esfera de lo privado, para sostener la necesidad de un ámbito reservado a un tipo de situaciones o relaciones interpersonales en donde la selección de los participantes depende de la libre decisión de cada individuo. Susana quería bañarse sola; Diana aceptaba únicamente la compañía de las ninfas, aquellas que, según Ovidio, «al ver entrar a un hombre empezaron a golpearse el pecho» e intentaron protegerla agolpándose a su alrededor. ${ }^{12}$ El círculo de estas ninfas fijaba el límite de lo privado, de lo vedado a la mirada ajena. En el caso de Sara Ferguson el velo protector es mucho más tenue y, por lo tanto, menos excluyente.

Según Avishai Margalit, los esquimales, que deben vivir juntos durante meses en un mismo igloo, «[r]ealizan sus actividades sexuales en perfecto silencio. Procuran que sus necesidades físicas sean llevadas a cabo de forma tal que nadie las perciba.» ${ }^{13}$

Cuáles sean los límites de la privacidad es algo que depende del contexto cultural y social. Sobre ello volveré más adelante.

Lo público está caracterizado por la libre accesibilidad de los comportamientos y decisiones de las personas en sociedad. El principio de publicidad es una característica esencial de todo Estado de derecho. Ningún liberal puede negarlo.

En el apéndice II de La paz perpetua, Kant subraya el carácter trascendental de la publicidad: sin ella «no habría justicia (que sólo puede ser pensada como públicamente manifiesta) ni habría tampoco derecho, que sólo se otorga desde la justicia.»

${ }^{11}$ Cfr. al respecto, Amartya Sen, «Liberty and social choice» en William James Booth, Patrick James y Hudson Meadwell (eds.), Politics and Rationality, Cambridge: University Press 1993, págs. 11-32.

${ }^{12}$ Ovidio, op. cit., pág. 143.

${ }^{13}$ Avishai Margalit, The Decent Society, cit., pág. 203. 
Y más concretamente:

«Después de prescindir de todo lo empírico que contiene el concepto de derecho político y de gentes [...] se puede denominar fórmula trascendental del derecho público a la siguiente proposición:

"Son injustas todas las acciones que se refieren al derecho de otras personas cuyos principios no soportan ser publicados."

No hay que considerar a este principio como un mero principio ético (perteneciente a la doctrina de la virtud) sino que hay que considerarlo también como un principio jurídico (que afecta al derecho de los hombres). Un principio que no pueda manifestarse en alta voz sin que se arruine al mismo tiempo mi propio propósito, un principio que, por lo tanto, debería permanecer secreto para poder prosperar y al que no puedo confesar públicamente sin provocar indefectiblemente la oposición de todos, un principio semejante sólo puede obtener esta universal y necesaria reacción de todos contra mí, cognoscible a priori, por la injusticia con que amenaza a todos.» ${ }^{14}$

El principio de publicidad se convierte en Kant, por razones conceptuales, en principio de legitimidad: sólo aquellas acciones y propósitos que pueden ser expresados abiertamente son legítimos. ${ }^{15}$

Si lo íntimo estaba caracterizado por su total opacidad, lo que caracteriza a lo público es la transparencia. Entre estos dos extremos cabría ubicar el ámbito de lo privado como aquél en donde impera una transparencia relativa. En efecto, la privacidad, tal como aquí es entendida, requiere necesariamente la presencia de, por lo menos, dos actores. Es la interacción entre ellos lo que impide la adopción de una total opacidad ya que ella volvería imposible toda comunicación. En el ámbito de lo privado, la discreción es sustituida por reglas de comportamiento muchas de ellas válidas sólo dentro del ámbito privado pero cuya calidad moral no depende exclusivamente de la capacidad de imposición por parte del legislador privado ni del consenso de sus destinatarios. La moral privada no es una moral diferente de la pública sino que ambas son manifestaciones de una única moral. Conviene no caer en la tentación weberiana de establecer una distinción tajante entre moral de la convicción y moral de la responsabilidad.

\section{2}

Supongamos que estamos dispuestos a aceptar estas propuestas conceptuales. La cuestión que de inmediato se plantea con respecto a nuestro tema

${ }^{14}$ Immanuel Kant, «Zum ewigen Frieden. Ein philosophischer Entwurf» en Werke, Francfort del Meno: Insel 1964, tomo VI, págs. 191-251, pág. 244 (citado según la versión castellana de Joaquín Abellán, La paz perpetua, Madrid: Tecnos 1985, págs. 61 s.).

${ }^{15}$ Con respecto a la vinculación entre publicidad y legitimidad en Kant, cfr. John Christian Laursen, «The Subversive Kant» en Political Theory, Vol. 14, No 4, noviembre 1986, págs. 584-603. 
es la de saber cuáles son las relaciones que existen entre estos tres tipos de esferas o ámbitos y hasta qué punto es moralmente legítimo expandir o reducir el alcance de cada uno de ellos en detrimento del de los otros dos.

Para el tratamiento de esta cuestión quisiera sugerir el recorrido de dos vías que transcurren en direcciones opuestas. La primera avanza desde lo íntimo hasta lo público; la segunda desde lo público hasta lo íntimo.

Veamos la primera. Ésta es una vía en donde el paso de un ámbito a otro es, desde luego, necesario para la supervivencia pero entraña también peligros vinculados con el grado de desvelamiento y con la oportunidad del mismo.

Por lo pronto, si se admite que el velo que protege la intimidad puede ser levantado sólo por el individuo en uso de su discreción, no habría mayor inconveniente en aceptar que si alguien desea hacerlo puede, en principio, desvelar la intimidad de su personalidad. Hasta qué punto esto es totalmente posible es algo más que dudoso. En todo caso, la redacción de diarios personales o de autobiografías suelen apuntar en esta dirección. Pero, no hay que olvidar que el desvelamiento de la propia intimidad significa la eliminación o la reducción de lo secreto, de sentimientos y pensamientos muchas veces confusos o transitorios, difíciles de ser aprehendidos cabalmente por otro. El peligro de ofrecer una versión distorsionada de nuestra propia personalidad es, por ello, muy grande. Podría pensarse, en este sentido, que la idea de la discreción hobbesiana está de alguna manera vinculada con la noción de autorrespeto. En el complicado proceso de elaboración de nuestra propia identidad, deseamos conservar para nosotros mismos la selección de aquellos planes o intenciones que estamos dispuestos a convertir o no en acciones externas. Pero también existe otro peligro: la desvelación unilateral de un secreto o la posibilidad de que algún otro tenga acceso a él nos colocan en situación de inferioridad en nuestras relaciones interpersonales. Como ha observado Sissela Bok:

«No poder tener secretos significa perder el control acerca de cómo los demás nos miran; nos deja librados a la coerción». ${ }^{16}$

Ello explica por qué la revelación voluntaria de nuestra intimidad solemos hacerla sólo en casos de relaciones excepcionales como las que crea el amor o un cierto tipo de amistad que justamente llamamos «íntima». En estos casos la revelación suele ser recíproca y es considerada como la forma más auténtica de entrega al otro. Está también, desde luego, la transmisión de secretos al confesor o a su versión laica, el psicoanalista. Cuán grande es la dependencia que esta relación unilateral puede crear lo saben muy bien los católicos y no pocos pacientes.

\footnotetext{
${ }^{16}$ Sissela Bok, Secrets. On the Ethics of Concealment and Revelation, Oxford: University Press 1984, pág, 19.
} 
En el ámbito de lo privado, aceptamos reglas de convivencia que, por una parte, tienden a preservar nuestra intimidad y, por otra, erigen barreras a la invasión de lo público. También en este ámbito hay comportamientos que preferimos realizar a solas y pensamientos que guardamos celosamente. El ámbito de lo privado es reducido por lo que respecta al número de sus miembros y puede presentar diversas características según la naturaleza de las relaciones interpersonales que en él se desenvuelven. Es muchas veces también el ambiente más propicio -por ser, en general, menos peligroso para desvelar, al menos en parte, nuestra intimidad. Y, como el ámbito de lo privado es el del dominio supuestamente irrestricto de nuestra libertad personal, solemos movemos en él procurando otorgar la mayor vigencia posible a nuestras preferencias.

Al ingresar al ámbito de lo público, seguimos llevando con nosotros mismos la coraza de la intimidad y el manto de la privacidad. Esta actitud crea situaciones ambiguas cuando no paradójicas.

En efecto, entramos en la esfera de lo público con cierto disimulo, tratando de preservar nuestra íntima personalidad y el área de nuestra privacidad, pero deseando que las decisiones públicas -si es que nos movemos dentro del marco de una democracia liberaltomen en cuenta el orden de las preferencias individuales, es decir, sean expresión de nuestra libertad personal. Aspiramos entonces a ser en la esfera pública liberales paretianos conservando, a la vez, irrestricto nuestro ámbito de libertad personal. Como todos sabemos, esta doble aspiración ha dado lugar a una célebre paradoja que sigue ocupando la mente y la pluma de no pocos teóricos de la elección racional.

Pero no sólo surgen situaciones paradójicas sino también comportamientos ambiguos. La ambigüedad reside en el hecho de que nuestra convivencia pública nos obliga, por lo pronto, a practicar aquello que Thomas Hobbes llamaba «pequeña moral» (Small Morafis):

«la decencia del comportamiento; cómo debemos saludarnos, cómo debemos lavarnos la boca o escarbar nuestros dientes antes de entrar en compañía $[\ldots] \gg{ }^{17}$

Los comportamientos que prescribe esta Small Moralls suelen adoptar una versión relativamente inofensiva que llamamos cortesía. Así, por ejemplo, el simple saludar al vecino o al conocido o el ceder el asiento a una dama en el autobús no parecen tener mayores implicaciones negativas y las aceptamos como conductas moralmente irrelevantes o hasta encomiables.

Pero, como la cortesía tiene una genealogía que se remonta a la defensa de la intimidad y de la privacidad, sus reglas no exigen o hasta prohíben la veracidad, el desvelamiento de nuestras intenciones y de nuestros intereses.

\footnotetext{
${ }^{17}$ Thomas Hobbes, Leviathan, cit., pág. 49. (Versión castellana, pág. 86).
} 
No sólo en Oxford, como recuerda Thomas $\mathrm{Nagel}^{18}$, sino en prácticamente todas las sociedades occidentales cuando alguien le dice a otro «Tenemos que comer juntos algún día de estos» ello significa que nunca comerán juntos. Y quien, siguiendo reglas de cortesía, pregunta a otro cómo le va no espera, desde luego, ni un informe veraz ni mucho menos completo. Lo primero podría ser inquietante y lo segundo tedioso:

«Es poco cortés llamar la atención sobre nuestros propios éxitos o expresar inseguridad personal, envidia, temor ante la muerte o sentimientos vehementes sobre personas presentes, excepto en un contexto de intimidad, en donde es posible tratar estos temas y explayarse al respecto»..$^{19}$

Este primer paso de salida del ámbito de lo privado hacia lo público está caracterizado, pues, por una reducción de la veracidad. Ésta es una característica que encierra el núcleo de una, para muchos peligrosa, hipocresía. Una vez más, valga aquí una cita algo extensa de Nagel:

«La idea liberal en la sociedad y la cultura, al igual que en la política, es que sólo puede ser objeto de pedido de respuesta pública aquello que es necesario porque así lo requiere la vida colectiva. Hasta dónde ello debe llegar es algo que depende de la compañía y de las circunstancias. Pero la idea de que todo es juego limpio y que la vida es mejor cuanto más apertura exista, más franqueza y más consenso es un grave error. El intento de imponerla conduce más bien a un tipo de hipocresía y mendacidad defensivas acerca de los propios sentimientos verdaderos que son innecesarias en un régimen de reticencia. Si vuestros pensamientos impuros u hostiles o políticamente agresivos están al alcance de cualquiera, tendréis razones para expresar en su lugar pensamientos benevolentes y patrióticos. [...] La decadencia de la privacidad trae consigo el surgimiento de la hipocresía.. ${ }^{20}$

Conviene detenerse en esta última frase de Nagel. Por una parte, es verdad que la reducción del ámbito de lo privado puede provocar un aumento de la hipocresía pública. Pero, por otra, también lo es que la hipocresía es un resultado de la persistencia de los valores (o disvalores) que profesamos en el ámbito de lo privado. Justamente porque suele existir una cierta divergencia entre lo que sostenemos en privado y lo que proclamamos públicamente es que se produce el fenómeno de la hipocresía. Como acertadamente observa Judith N. Shklar:

«En los Estados Unidos ya no se acepta que alguien exprese públicamente comentarios racistas o antisemitas; sin embargo, en la conversación privada el racismo y el antisemitismo se expresan libre y frecuentemente. [...] ¿Preferiría algún igualitarista una mayor franqueza pública? ¿Debería ser nuestra conducta

\footnotetext{
${ }^{18}$ Thomas Nagel, «Concealment and Exposure» en Philosophy \& Public Affairs, Vol. 27 (Winter 1998), N ${ }^{\circ}$ 1, págs. 3-30, pág. 6 .

${ }^{19}$ Thomas Nagel, «Concealment and Exposure», cit., pág. 13.

${ }^{20}$ Thomas Nagel, «Concealment and Exposure», cit., pág. 14.
} 
pública realmente el espejo de tal como somos privada e íntimamente? A menudo nuestros modales públicos son mejores que nuestra laxitud personal [...] En verdad, podría aducirse que nuestra democracia liberal no puede permitirse la sinceridad pública. La honestidad que humilla y el rechazo terco del compromiso arruinaría la civilidad democrática en una sociedad política en la que la gente tiene muchas y serias diferencias de creencias e intereses.. ${ }^{21}$

Y una forma de hipocresía muy difundida en nuestras sociedades es la llamada political correctness que no pocas veces impone comportamientos que nos parecen ridículos o hasta el colmo de la mendacidad. Dicho sea de paso, conviene señalar que esta expresión fue formulada por primera vez hace doscientos años, no en los Estados Unidos sino en Alemania. En efecto, en las Literarischen Notizen 1797 bis 1801 de Friedrich Schlegel aparece ya la expresión «politische Correctheit». Schlegel quería denotar con ella el trato respetuoso con los demás o, dicho con sus propias palabras la «interpretación mística de las conveniencias de la cortesía» («mystischen Deutung der Höflichkeitsconvenienzen»). ${ }^{22}$

Small Moralls, cortesía, political correctness e hipocresía tienen un núcleo común: son formas de comportamiento que responden a una serie de reglas que nos ayudan a traspasar con posibilidades de éxito los límites de lo privado. Su violación puede alterar la naturaleza de una misma acción: usar prendas íntimas en público puede ser motivo de escándalo. La manida discusión sobre la pornografía gira justamente alrededor de los límites de lo privado y lo público en el campo de las relaciones sexuales.

Son estas reglas, pues, las que nos ayudan a desempeñar papeles sociales. No está demás recordar que el origen etimológico de la palabra «hipocresía» es jugar un papel en el teatro. Buena parte de nuestra vida en sociedad está constituida por roles que debemos desempeñar y donde no siempre la franqueza es la mejor guía. No es verdad que la verdad no ofende y andar por el mundo dando puñetazos de verdades puede ser una de las formas más peligrosas y nocivas de la actuación social. No hace falta ser Yago para suscribir su reflexión:

« Oh mundo monstruoso! toma nota, toma nota, joh mundo!

Ser franco y honesto, no es prudente. $»^{23}$

Desde luego, puede seguirse insistiendo en que la veracidad es condición necesaria para el establecimiento de una sociedad justa dentro de marcos liberales. Los esfuerzos realizados por autores como Jürgen Habermas

${ }^{21}$ Judith N. Shkfar, Ordinan. Vices, Cambridge Mass., Harvard University Press, 1984, pág. 78.

${ }^{22}$ Cfr. Frank Lucht, «Schlaflose Náchte Zweihundert Jahre "P.C.”» en el Süddeutsche Zeitungy, Múnich, 9 de abril de 1997, pág. 13.

${ }^{23}$ William Shakespeare, Otelo, acto III, escena 3. 
y John Rawls para imaginar situaciones de discurso en los que las partes que intervienen en el diálogo habrán de encontrar finalmente principios fundamentales para el diseño futuro de la sociedad parten de la suposición de que la veracidad es condición necesaria de esta empresa. También Rousseau creía que la democracia sólo podía funcionar si las personas renunciaban a su egoísmo y actuaban en la vida pública como seres morales dispuestos siempre a aceptar la volonté général. Pero esto implicaba una fuerte renuncia al intento de hacer prevalecer las preferencias individuales, es decir, a conservar intacto el ámbito de lo privado. Rousseau percibió claramente esta fuente de conflicto entre lo privado y lo público:

«En efecto, si bien no es imposible que una voluntad particular concuerde en algún punto con la voluntad general, sí lo es, al menos que esta armonía sea duradera y constante, porque la voluntad particular tiende por su naturaleza al privilegio y la voluntad general a la igualdad.. ${ }^{24}$

Paradójicamente, la democracia liberal, en tanto forma de gobierno que supuestamente está destinada a dar prioridad a las preferencias individuales, tiene que aceptar, si quiere ser estable, una buena dosis de reducción de la vigencia de estas mismas preferencias. Éste es el precio que la igualdad requiere. Si ello es así, entonces la honestidad y la veracidad, virtudes apreciadas en alto grado por todo demócrata liberal, resultan socavadas por las propias exigencias del régimen democrático. Ante esta situación, quien desee contribuir a la estabilidad de la democracia y, al mismo tiempo, ser leal a buena parte de sus tendencias egoístas que arrancan de lo más íntimo de su personalidad, tiene que ser hipócrita. Un régimen político estable no puede basarse exclusivamente en la calidad de agentes morales de los ciudadanos. Esto era algo que lo habían percibido claramente Maquiavelo y Rousseau; pero mientras el primero veía aquí buenas posibilidades de manipulación política, el segundo no podía dejar de inquietarse ante la influencia corrosiva de los intereses privados. Kant, el pensador que con mayor claridad vio la imposibilidad de concebir un ser moral no desprendido de sus peculiaridades empíricas personales, propiciaba por ello un sistema político que pudiera regir en una sociedad de egoístas que querían vivir en sociedad. Su idea de la «sociabilidad asocial» («ungesellige Geselligkeit») ${ }^{25}$ condensa esta idea.

Habermas y Rawls cometen aquí un pecado de irrealidad y exigen demasiado del ser humano. Tal vez lo único que se requiere para la vida en democracia es la proclamación de ciertos valores, aunque esta proclamación

${ }^{24}$ Jean-Jacques Rousseau, «Du Contrat Social; ou, Principes du Droit Politique» en Oeuvres complètes, París: Gallimard, tomo III, págs. 347-470, pág. 368.

${ }^{25}$ Inmanuel Kant, «Idee zu einer allgemeinen geschichte in weltbürgerlicher Absicht» en Werke, Francfort del Meno: Insel 1964, tomo VI, págs. 31-50, pág. 37. 
sea puramente retórica, es decir, que actuemos como si adhiriésemos a los valores proclamados. Esta adhesión retórica es suficiente; pero la adhesión retórica a valores no sustentados íntimamente es lo que llamamos hipocresía. François de la Rochefoucauld podía decir por ello, con razón que «la hipocresía es el homenaje que el vicio rinde a la virtud». Dicho con otras palabras: ¡si no puedes ser moral, al menos sé hipócrita! Creo, por ello, que tiene perfecta razón Ruth W. Grant cuando afirma:

«A pesar de que los regímenes democráticos liberales son los que más necesitan la honestidad como virtud política, son justamente ellos los que más probablemente crean las condiciones que socavan esta virtud. [...] el liberalismo puede ser criticado no por ser hipócrita sino por negarse a reconocer la necesidad de la hipocresía». ${ }^{26}$

Entramos, pues, en el ámbito de lo público con nuestra carga de preferencias privadas (no todas ellas benevolentes) y con una mezcla de honestidad e hipocresía-, justamente porque sabemos que no podemos subsistir en nuestro estrecho recinto de lo privado, formulamos y aceptamos (aunque sólo sea retóricamente) reglas más exigentes que imponen una severa limitación a nuestros deseos egoístas. Sabemos que para que la empresa social sea exitosa tenemos que admitir dos principios básicos: la prohibición de dañar al prójimo (el harm principle tan claramente formulado por Mill) y la obligación de contribuir a la generación de bienes públicos, es decir, de renunciar a comportamientos parasitarios. ${ }^{27}$ En este sentido, la vigencia de las reglas de convivencia con seres que muchas veces nos disgustan y cuyas preferencias personales no compartimos, nos obliga a ser o a aparentar ser morales.

Vistas así las cosas, el avance desde la intimidad hacia lo público es una marcha hacia una mayor moralidad en el comportamiento real de las personas. Ello no se logra conservando o estimulando las notas de lo íntimo o de lo privado sino justamente al revés, acallándolas o restringiéndolas. Para decirlo con palabras de Kant:

«El problema del establecimiento del Estado tiene solución, incluso para un pueblo de demonios [...] y el problema se formula así: "ordenar una muchedumbre de seres racionales que, para su conservación, exigen conjuntamente leyes universales, aun cuando cada uno tienda en su interior a eludir la ley, y establecer su constitución de modo tal que, aunque sus sentimientos particulares sean opuestos, los contengan mutuamente de manera que el resultado de su conducta pública sea el mismo que si no tuvieran tales malas inclinaciones." ${ }^{28}$

${ }^{26}$ Ruth W. Grant, Hypocrisy and Integrity. Machiavelli, Rousseau, and the Ethics of politics, Chicago/Londres: The University of Chicago Press 1997, págs. 175 s.

${ }^{27}$ Agradezco a Ruth Zimmerling el haberme recordado la importancia de la generación de bienes públicos para la convivencia social.

${ }^{28}$ Inmanuel Kant, «Zum ewigen Frieden. Ein philosophischer Entwurf» en Werke, cit., 224 (citado según la versión castellana de Joaquín Abellán, La paz perpetua, cit. págs. $38 \mathrm{~s}$. 
La creación de un orden jurídico liberal (o republicano en la terminología de Kant) cumple así una función moralizante precisamente porque se basa en una concepción general de lo bueno público. Las críticas de Michael J. Sandel al llamado «liberalismo minimalista» («minimalist liberalism») no valen para un liberalismo de tipo kantiano, como él mismo lo reconoce. ${ }^{29}$ Pero, ello no se debe a una concepción de la persona como agente moral sino a la función que Kant atribuye al Estado republicano:

«los hombres se aproximan mucho en su conducta externa a lo que prescribe la idea del derecho, aunque con toda seguridad no es la moralidad la causa de ese comportamiento (como tampoco es causa de la buena constitución del Estado, sino más bien al contrario; de esta última hay que esperar la formación moral de un pueblo)». ${ }^{30}$

La discusión acerca de la prioridad de los derechos sobre las concepciones de lo bueno, que tanto ha agitado los ánimos en el ámbito anglosajón y que suele ser tomada en cuenta para delimitar la relación entre lo privado y lo público, debería no olvidar que para un coherente liberal kantiano la neutralidad moral del Estado no llega al extremo de privilegiar incondicionalmente lo privado sobre lo público ni las decisiones individuales sobre las decisiones públicas. La autonomía kantiana tiene poco que ver con las decisiones dentro del ámbito privado, si es que se entiende a este último como el campo de una libertad sólo sujeta, en el mejor de los casos, a restricciones tradicionales o comunitarias. Este tipo de privacidad no es el de un «unencumbered self» que luego proyectaría sus fines al ámbito público. Si se toma en serio la frase de Kant que acabo de recordar, cuesta (al menos a mí me cuesta) inferir como Sandel que

«[p]ara los liberales kantianos, precisamente porque somos seres independientes, que eligen libremente, necesitamos una estructura neutral, una estructura de derechos que se niegue a elegir entre valores y fines competitivos. $\rangle^{31}$

Una neutralidad tan extrema, un respeto tan grande por el ámbito de lo privado, no podría realizar la función pedagógica que Kant atribuye a una constitución republicana. Tal vez los malos entendidos de la discusión Sandel-Rawls se deban a que el primero atribuye al segundo una ortodoxia kantiana no siempre sostenible. ${ }^{32}$ Pero, aun cuando se tome como punto de referencia

\footnotetext{
${ }^{29}$ Cfr. Michael J. Sandel, Democracy's Discontent. America in Search of a Public Philosophy, Cambridge, Mass.: Harvard University Press 1998, pág. 103.

${ }^{30}$ Immanuel Kant, «Zum ewigen Frieden. Ein philosophischer Entwurf» cit., pág. 224. Citado en la versión castellana de Joaquín Abellán, cit., pág. 39.

${ }^{31}$ Michael J. Sandel, op. cit., pág. 12.

${ }^{32}$ Kant, por ejemplo, no aceptaría sin más la afirmación de Rawls según la cual «hablando estrictamente, los ciudadanos en general no tienen una obligación política», que Sandel cita como argumento en contra de los liberales kantianos. Basta pensar en la concepción kantiana sobre el derecho de resistencia y en su aversión a todo tipo de actitud revolucionaria.
} 
las últimas obras de Rawls, especialmente Political Liberalism ${ }^{33}$, y se califique su posición como la de un minimalist liberalism ${ }^{34}$, no veo por qué no ha de poder aceptarse la separación entre nuestra identidad como ciudadanos y nuestra identidad como personas. La calidad moral de un sistema político no depende necesariamente de la calidad moral de las personas. La legitimidad de un sistema político, si se la entiende como la coincidencia de sus principios y reglas con los principios y reglas de una moral crítica, puede ser impuesta heterónomamente; no así, en cambio, la moral individual, que siempre presupone una aceptación autónoma de estos principios y reglas. ${ }^{35} \mathrm{Y}$ porque el paso de lo privado a lo público puede y hasta debe en algunos casos significar una restricción de nuestros deseos $\mathrm{y}$ preferencias personales es que en todas las constituciones democrático-liberales se establece una limitación a lo públicamente imponible desde el ámbito de lo privado. Esta limitación es justificable desde un punto de vista filosófico-moral que no tiene por qué ser necesariamente metafísico. Por ello creo que la disyuntiva que Sandel le plantea al liberal minimalista no es correcta:

«El argumento minimalista en favor del liberalismo depende de la plausibilidad de separar la política de la filosofía, de poner entre paréntesis la política con respecto a la filosofía, las cuestiones morales y religiosas en relación con la política. [...] Una forma de asegurar la prioridad de lo práctico es negar que alguna de las concepciones morales o religiosas que pone entre paréntesis podría ser verdadera. Pero éste es precisamente el tipo de pretensión metafísica controvertida que el liberal minimalista desea evitar.. ${ }^{36}$

La argumentación de Sandel adolece de una petitio principii: supone que toda justificación de principios o reglas morales escapa al control racional y nos conduce a la nebulosidad metafísica. Para que ello tuviera fuerza argumentativa, habría que demostrar la corrección de lo que se supone.

Pero, dejando de lado la discusión acerca de los derechos y las concepciones de lo bueno y retornando el hilo de la argumentación que vengo exponiendo, es obvio, me parece, que en la medida en que el papel que una persona desempeña en la sociedad tiene mayores connotaciones públicas la esfera de lo privado se reduce considerablemente ya que muchas veces es difícil trazar un límite preciso entre lo privado y lo público; los amores de Diana de Wales podían tener consecuencias institucionales y la obtención

${ }^{33}$ Nueva York: Columbia University Press 1993.

${ }^{34}$ Cfr. Michael J. Sandel, op. cit., págs. 17 ss.

${ }^{35}$ Con respecto a la relación entre de la legitimidad de un sistema político y la moralidad individual, cfr. Ernesto Garzón Valdés, «intervencionismo y paternalismo» en del mismo autor, Derecho, ética y política, Madrid: Centro de Estudios Constitucionales 1993, págs. 379-399.

${ }^{36}$ Michael J. Sandel, op. cit., pág. 19. 
de mandatos políticos vía procreación de hijos fuera del matrimonio son hechos que no dejan indiferente a la ciudadanía. Tampoco es indiferente para el destino político de una sociedad el conocimiento de la salud o de las expectativas de vida de los candidatos que se ofrecen, ellos mismos, para desempeñar la más alta magistratura de un país. Si ello es así, los médicos que conocían la gravedad de la enfermedad de Perón o de Mitterrand no sólo podían sino que debían comunicar estos datos. ${ }^{37}$ Que ello hubiera sido políticamente acertado lo demuestra la historia argentina contemporánea. Nadie pretende en nuestras sociedades (y desde luego es mejor que así sea, al menos por razones estéticas) que los presidentes sean sometidos al ritual de los monarcas franceses y practiquen una versión actualizada de «la levée du Roi» o que institucionalicen a sus amantes y las equiparen a las «maitresses» versallescas. La relevancia política de las aventuras amorosas de Clinton tiende a cero. En cambio, sí parece más relevante conocer el patrimonio privado de los gobernantes y el origen de una fortuna acrecentada durante los años de gobierno.

Así pues, como la exigencia de transparencia es mayor, la tolerancia ante la hipocresía es menor. La crítica de la corrupción (es decir a una forma de comportamiento que podría ser calificada de hipócrita) es implacable cuando se trata de gobernantes o de jueces. Y está bien que así sea.

¿Qué pasa ahora con la marcha en la dirección inversa, es decir, desde lo público hacia lo privado y lo íntimo?

La cada vez más intensa «invasión» de lo público en lo privado es motivo de manifiesta inquietud. Convendría detenerse a considerar cuáles son las razones de este desasosiego y procurar deslindar las buenas de las malas.

Por lo pronto, para alguien que adopte una posición comunitarista, es decir, para alguien que privilegie la relevancia moral de los grupos pequeños, clanes o familias, el avance de lo público tiene que parecerle básicamente peligroso, también para la identidad personal. En efecto, un comunitarista coherente no puede aceptar la interpretación que aquí he presentado de los pasos que conducen desde la intimidad a lo público.

La idea de la comunidad como punto de partida para la formulación y puesta en práctica de una justicia distributiva, por ejemplo, ha sido sostenida por no pocos autores de orientación comunitarista: se parte de una idealización de la solidaridad existente en el clan y se avanza luego hacia la creación de un Estado de bienestar en el que se crearían relaciones de «ayuda

${ }^{37}$ Sé que esto violaría una de las conclusiones de la Nordic Conference on the Right of Privacy (cfr. Richard B. Parker, «A definition of privacy» en Burton M. Leiser (ed.), Values in Conflict. Life, Liberty and the Rule of Law, Nueva York: Macmillan 1981, págs. 277-296, pág. 279) en el sentido de que estaría moralmente prohibido revelar informaciones obtenidas «en circunstancias de confidencia profesional», pero creo que esta violación es legítima. 
mutua» y de «altruismo recíproco», en donde imperaría algo así como el «equivalente político del amor», como diría Roberto Mangabeira Unger. ${ }^{38}$

Este paso del clan familiar, de la esfera de lo privado, hacia el ámbito público del Estado social me parece más que problemático. Por lo pronto, la institucionalización del supuestamente existente altruismo familiar o de clan difícilmente puede ser entendida como el origen del Estado de bienestar. En efecto:

«[a]l institucionalizar el altruismo -volviéndolo así impersonal y obligatorio- el estado social altera fundamentalmente la naturaleza del altruismo que motiva la ayuda mutua en sociedades aldeanas. $\gg{ }^{39}$

El Estado de bienestar no es una mera reformulación de una solidaridad supuestamente dada en las comunidades pequeñas sino que está basado en la imposición coactiva, a través de la vía fiscal, de una redistribución de bienes cuya vigencia no depende de la actitud subjetiva del contribuyente. No se trata aquí de encontrar un «equivalente político del amor». Hablar de un amor obligado es un sinsentido como lo es el de un altruismo coaccionado. No existe, pues, una vía directa que conduzca de la postulada solidaridad en la esfera privada al Estado de bienestar ya que se trata de dos niveles diferentes de cuestiones y el paso del uno al otro requiere construcciones institucionales que no derivan, por así decirlo, «naturalmente» de la solidaridad familiar o comunitaria. Son las instituciones las que confieren derechos sociales inmunes a los sentimientos de simpatía o antipatía de los miembros mejor situados en la sociedad:

«Hacer que un derecho dependa para su realización de las actitudes positivas de aquellos a quienes les impondría una obligación equivale a aniquilar este derecho. ${ }^{40}$

Pero tampoco es plausible afirmar sin más que el ámbito de lo privado sea siempre el más armónico de los mundos sociales. Una somera lectura de algunas tragedias, desde los griegos hasta Shakespeare nos ilustra acerca de la falsedad de esta suposición.

El argumento comunitarista no parece ser muy convincente. En todo caso, es difícil de aceptar para un liberal.

Pero, hay otra línea de argumentación que quizás pueda ser más sugerente. Es la propuesta por Benjamin Constant. Como es sabido, según él, la libertad de los modernos debía ser distinguida claramente de la libertad de

${ }^{38}$ Citado según Robert E. Goodin, Reasons for Welfare. The Political Theory of the Welfare State, Princeton: Princeton University Press 1988, pág. 77.

${ }^{39}$ Cfr. Robert E. Goodin, op. cit., pág. 115.

${ }^{40}$ Cfr. Daniel M. Weinstock, «Is There a Moral Case for Nationalism?» en Journal of Applied Philosophy, Vol. 13, № 1, 1996, págs. 87-100, aquí pág. 92. 
los antiguos. Mientras esta última consistiría en la participación activa y constante en el ejercicio del poder colectivo, la primera residiría en el «disfrute apacible de la independencia privada» ${ }^{41}$.

En la concepción de Constant, buena parte de los derechos individuales estaban centrados en la protección de la privacidad. Y no deja de ser instructivo que este viejo liberal considerase que una de las típicas manifestaciones del respeto debido a la vida privada era el secreto de las cuentas del banquero «a las que nadie salvo él debe tener acceso». ${ }^{42}$

A mediados del siglo XVIII, una aristócrata parisina, la marquesa Louise d'Epinay, resolvió, en un acto de ilustrada democracia, enviar a sus hijos a una escuela pública. Había así abierto una parte de su ámbito privado y permitido la intromisión del Estado en un campo hasta estonces exclusivamente privado cual era el de la educación de la nobleza. Esta decisión impresionó tanto a su amigo Rousseau que, según parece, el filósofo se inspiró en su caso y escribió el Emilio. ${ }^{43}$

El caso del banquero de Constant y el de los hijos de Louise d'Epinay se nos presentan en la actualidad como algo extravagantes. Todo ciudadano de una sociedad democrática y liberal estaría dispuesto a aceptar que las inspecciones de los ministerios de Finanzas y la imposición de la educación pública obligatoria son «invasiones» en la esfera privada justificables sólo si está dispuesto a ceder una parte de la autonomía familiar. Con respecto al problema de la obligatoriedad escolar, en 1983, James S. Fishkin dedicó un sugestivo libro al análisis de hasta qué punto un liberal puede admitir la intervención del Estado en el ámbito familiar, o sea, la violación de la autonomía familiar (de la privacidad familiar, podríamos decir), para regular la educación de los niños y asegurar así la vigencia de los principios de igualdad de oportunidades y de no discriminación por razones de raza, sexo o clase social. ${ }^{44}$ Según Fishkin, aquí surgiría un trilema en cuya consideración no quiero ahora detenerme. Lo importante es subrayar que sólo cediendo parte de la autonomía familiar es posible asegurar una mayor justicia en el ámbito público. Entre el padre que, en aras de la conservación de sus preferencias privadas, prohíbe a su hijo la participación en un sistema educativo que le ofrece mejores oportunidades en el ámbito público y el que admite

\footnotetext{
${ }^{41}$ Benjamin Constant, Cours de Politique Constitutionelle, París: Didier 1836, pág. 547.

${ }^{42}$ Benjamin Constant, «De la liberté des brochures, des pamphlets et des journaux, considéréé sous le rapport de l'intéret du gouvernement» en Oeuvres, París: Gallimard 1957, pág. 1236, citado según Helena Béjar, El ámbito intimo. Privacidad, individualismo y modernidad, Madrid: Alianza 1988, pág. 44.

${ }^{43}$ Cfr. Elisabeth Dadinter, Emilie, Emilie. Weiblicher Lebensentwurf im 18. Jahrhundert, Múnich: Piper, 1984.

${ }^{44}$ James S. Fishkin, Justice, Equal Oportunity, and the Family, New Haven/Londres 1983.
} 
la «invasión» de lo público, pienso que hay mejores razones morales en favor de este último.

También el control fiscal sirve propósitos de justicia distributiva. No hay duda que una inspección fiscal no es lo más agradable del mundo, pero ello suele deberse a una cierta «mala conciencia» que todo contribuyente tiene; invocar el principio de privacidad en estos casos no sólo sería inoperante sino también hasta una manifestación del deseo de ocultar infracciones impositivas.

En casi todas las sociedades (no sólo en las liberales) las actividades sexuales suelen constituir un caso típico del ejercicio de comportamientos propios de la esfera privada. La oportunidad y la forma como ellas se realizan sería cuestión de cada cual. Ya no existe ni el ius prima noctis ni la exigencia de demostrar la consumación del acto sexual exhibiendo sábanas ensangrentadas. Pero tampoco está permitida cualquier forma de relación sexual. Las feministas han insistido, con buenas razones, en la necesidad de castigar la violación dentro del matrimonio. La invasión del derecho penal en el hogar ha contribuido, quizás, a la reducción de este tipo de delito, al igual que de los casos de abuso sexual de menores.

Los ejemplos de intervenciones en la esfera privada que todo liberal puede defender racionalmente podrían multiplicarse. Común a todos estos casos es la ampliación de la esfera pública con miras a salvaguardar los dos principios que hacen posible una supervivencia aceptable: la prohibición del daño a terceros (como en el caso de la violación dentro del matrimonio) y la contribución a la creación de bienes públicos (como en el caso de la evasión fiscal y la educación de las nuevas generaciones). La esfera privada no puede, en este sentido, ser un coto reservado para la comisión de delitos. No hay duda que toda intervención en la esfera privada significa una reducción del control individual pero de aquí no puede inferirse sin más, como lo hace Avishai Margalit, que exista siempre una

«relación causal entre la violación de la privacidad y la humillación en el sentido de pérdida de control». ${ }^{45}$

La pérdida del control significa, sin duda, una reducción del poder en el ámbito privado pero ello no significa necesariamente una humillación. Una sociedad no deja de ser decente porque no admita la impunidad en la esfera privada. Sería realmente grotesco que Jack el Destripador invocara el respeto a su privacidad alegando que nadie puede entrar en su baño cuando está entregado a la «tarea privada» de serruchar a su mujer en la bañera. Un argumento semejante tampoco habría convencido a James Stewart para que apartara su catalejo y dejara de observar al gordo siniestro que empaquetaba maletas

${ }^{45}$ Avishai Margalit, The decent Society, cit., pág. 207. 
y cavaba la fosa en su jardín para depositar el cadáver de su cónyuge. Y me inclino a creer que Silvia Belawsky no actuó inmoralmente cuando informó públicamente las conversaciones privadas mantenidas con su marido.

Hasta aquí parece, pues, que algunas invasiones de lo público en lo privado tienen fundamentos morales aceptables. La cuestión es ahora terminar este recorrido y pasar de la privacidad a la intimidad. Dicho con otras palabras: ¿puede permitirse moralmente la inspección de la persona no ya en su relación externa con otras sino en aquellos casos en los que está físicamente sola, realizando actos que no afectan a terceros? ¿Qué sucede con los pensamientos de una persona, podemos admitir la licitud moral de la Thought-police?

Si se aceptan los dos principios de la organización social pública a los que me he referido reiteradamente, habrá que concluir que Diana (la del bosque) y Susana (la de la Biblia) tenían razón en sentirse humilladas ante la mirada indiscreta de Acteón o de los viejos de Babilonia. En estos casos, la humillación se debe no sólo a la mirada sino a la forma como subjetivamente se la percibe. Este aspecto subjetivo de la privacidad es el que cambia según las personas y las culturas. Algo de razón tiene Umberto Eco cuando afirma:

«En la actualidad, la persona común no desea la privacy. Si es cornudo, se apresura a ir a la televisión para litigar con el propio partner infiel delante de millones de espectadores; si padece de una enfermedad terrible, desfila en público con carteles para sostener los derechos de sus compañeros de desventura, usa compulsivamente el micrófono [...] y hasta el arrepentimiento es una forma explícita de renuncia a custodiar secretos terribles. [...] Se infiere de ello [...] que la verdadera tarea a que deberán hacer frente las distintas autoridades (que en los diversos países están empeñadas en la defensa de la privacy) no será la de asegurarla a los que la solicitan (relativamente pocos sobre el total de la población), sino de hacer que sea considerada un bien precioso por parte de los que entusiastamente han renunciado a ella». ${ }^{46}$

Efectivamente, el derecho a la privacidad, el «derecho del individuo a que lo dejen solo» (para no dejar de citar la fórmula de Louis Brandeis y Samuel Warren, lugar común de todo trabajo sobre la privacidad ${ }^{47}$ ) suele ser invocado cuando se desea ocultar comportamientos que pueden ser objeto de censura pública. Si Diana (la cazadora) podía formular la amenazadora frase «ve a contar por ahí que me has visto sin velos» y a los abogados de Boston les preocupaba hace 100 años «la vana chismografía que puede obtenerse sólo a través de la intrusión en la esfera doméstica» ${ }^{48}$, actualmente

\footnotetext{
${ }^{46}$ Cfr. La Nación, Buenos Aires, del 14 de junio de 1998, pág. 6, sección 7.

${ }^{47}$ Samuel Warren y Louis Brandeis, «The Right to Privacy» en Harvard Law Review, 4 (1890), págs. 193-220.

${ }^{48}$ Ibídem, pág. 196.
} 
buena parte de la fama de los «famosos» se basa en la autopropiciada exposición de sus desnudeces y en la chismografía que ellos mismos estimulan. Los nombres de Gennifer Flowers, Kathleen Willy, Paula Jones, Monica Lewinsky o de las Samanthas argentinas no serían conocidos más allá del círculo de sus familiares, colegas de oficina o vecinos del barrio si sus portadoras no se hubieran encargado de proclamar a todos los vientos que alguien realmente más famoso que ellas había intentado o realizado acciones que el común de los mortales practica sin mayor alharaca. A su vez, lo mismo parece sucederle a algunas personas famosas: la divulgación de sus acciones privadas tendría la benéfica influencia de aumentar el propio placer. Hasta la pacata (¿o no tanto?) Reina Victoria solía comentar públicamente: «La noche de bodas no dormimos mucho» (posiblemente pensaba que ésta era una experiencia vital que sólo a ella le estaba reservada) ${ }^{49}$ En todo caso, ahora, la fórmula de Diana se ha justamente invertido: «iAy de ti si no cuentas que me has visto sin velos!». Por ello, los paparazzi suelen no humillar a los objetos de sus fotos sino más bien satisfacer los deseos de las personas fotografiadas y de un público que lamenta no tener nada interesante para desnudar. Earl Spencer lo sabe.

¿Qué pasa con los pensamientos, con ese reducto último de la intimidad? Aquí parece que llegamos a una última barrera infranqueable. Pero esto se debe quizás no tanto a la posible inmoralidad de muchos de ellos, a aquello que a Goethe le hacía decir:

«Todos tenemos en nuestra naturaleza algo que, si públicamente se manifestase, por fuerza habría de provocar desagrado» ${ }^{50}$,

sino, porque muchas veces son expresiones de estados de ánimo o deseos fugaces cuya aparición no controlamos pero que luego reprimimos. Es en la intimidad donde forjamos nuestra identidad y las ideas o planes de acción que luego manifestamos en privado o en público si lo consideramos oportuno. No hace falta ser Isaac Newton para admitir que buena parte de nuestra personalidad es el resultado de lo que él describía como un proceso de incubación dentro del ámbito íntimo: Nocte dieque incubando. ${ }^{51}$ Por ello, la posibilidad

49 Para mayores datos sobre la vida de esta reina cuyo nombre es sinónimo de recato y salvaguarda de la vida privada, cfr. Carolly Erickson, La vida privada de la Reina Victoria, Madrid: Javier Vergara 1997.

${ }^{50}$ Johann W. Goethe, «Máximas y reflexiones» en Obras completas, tomo 1, Madrid: Aguilar 1974, pág. 345 .

${ }^{51}$ La frase de Newton es la respuesta que él dio cuando se le pregunto cómo había llegado a concebir la teoría de las leyes mecánicas del universo (cfr. David L. Norton, Democracy and Moral Development. A Politics of Virtue, Berkeley: University of California Press 1995, pág. 126) pero creo que vale también para la gestación de muchos de nuestros comportamientos y proyectos de vida que configuran la propia identidad. 
de irrumpir en la intimidad encierra el enorme peligro de una interrupción distorsionante de este proceso. La presentación pública de estados de ánimo y deseos transitorios o de gestos y actitudes que ni siquiera dejamos que ingresen en el ámbito de lo privado abre de par en par las puertas para la manipulación incontrolada de aspectos fragmentarios de nuestra intimidad que nada tiene que ver con lo que somos o con lo que queremos ser.

Sin embargo, en otros casos, cuando se trata de pensamientos o intenciones concluidos y/o expresados en acciones o actividades interpersonales, su conocimiento puede tener relevancia privada y/o pública. No le hubiera venido mal a la esposa del asesino observado por James Stewart conocer las intenciones de su marido; toda persona realmente enamorada desea que el o la amante conozca sus pensamientos y no mal interprete sus actos. Si queremos seguir buscando ejemplos cinematográficos, pensemos en la invitación de Humphrey Bogart a Ingrid Bergmann en Casablanca para que lo penetre con su mirada o si deseamos la ilustración literaria recordemos la frase de Romeo (la de Julieta):

«iAy! Veinte veces más peligrosos que todas las espadas son para mí los ojos tuyos. Con una simple mirada que me envíes, quedo a prueba de su rencor..» ${ }^{52}$

Dejemos de lado el ámbito del amor. También en otros campos nos interesa conocer la intención de las personas. Es ella la que nos permite distinguir el homicidio de la muerte culposa; el ánimo de ofender, de la frase dicha sin pensar. El efecto perlocucionario de las frases y palabras depende justamente de la intención con que son pronunciadas en determinadas circunstancias. Y cuando no hay confesión de parte, solemos valernos de indicios. Parecería, pues, que hasta este extremo podría llegar la intervención de lo público.

3

Si se acepta esta propuesta de recorrido de doble dirección entre los dos polos de lo íntimo y lo público pasando por lo privado, creo que podrían sacarse las siguientes conclusiones:

i. Cuando avanzamos hacia lo público (en una sociedad liberal y democrática) lo que hacemos es adquirir formas de comportamiento que posibilitan y dan estabilidad a una convivencia en paz y socialmente eficaz, al menos desde el punto de vista de la justicia retributiva y distributiva.

ii. Para el logro de estos fines es irrelevante el que cumplamos las reglas de lo público como seres morales o como agentes hipócritas; lo que importa es que aceptemos internamente la necesidad de la existencia de estas reglas.

iii. La defensa del ámbito de la privacidad no debe ser una garantía de impunidad.

${ }^{52}$ Romeo y Julieta, acto II, escena 2. 
iv. Porque ello es así, hay formas moralmente aceptables de irrupción de lo público en lo privado cuando lo que se realiza en este ámbito tiene consecuencias que afectan el principio de daño y/o el de colaboración para la producción de bienes públicos.

v. La revelación pública de aquellos actos realizados en privado y que no caen en la categoría de los mencionados en el párrafo anterior puede afectar la dignidad de la persona. En el mejor de los casos son meros chismes y, en el peor, humillan. La venganza de la Diana cazadora fue motivada por la conjunción de estos dos elementos.

vi. El problema de la relación entre intimidad, privacidad y publicidad no es tanto una cuestión de qué es lo que puede ser revelado sino de los métodos que se usen para combatir la impunidad.

vii. Pero si es un problema de métodos o de procedimientos técnicos, la prudencia aconseja ser cautos en la permisión de recursos cuyo manejo incontrolado sólo sirve para humillar con lo que se viola cual bumerang el principio de daño.

viii. En todo caso, si se plantea la discusión en términos de conflicto entre el principio de privacidad y el principio de publicidad, no es posible formular reglas fijas o inmutables para resolverlo sino que se vuelve necesario buscar para cada caso concreto la solución moralmente más plausible sabiendo que, en algunas circunstancias, puede tratarse de una elección trágica con todo lo que ello implica desde el punto de vista moral.

Lo aquí expuesto es sólo un intento de desacralizar lo privado, de rescatar la hipocresía de una satanización (curiosamente hipócrita) y de invitar a una mayor modestia con respecto a nuestras propias calidades morales íntimas. Tengo plena conciencia de que todo esto es un tema sumamente controvertido y que existen también razones plausibles, no sólo de tipo moral sino también prudenciales, en contra de la hipocresía. ${ }^{53}$

En todo caso, en el campo de la política conviene abandonar la idea de que los ciudadanos deben ser agentes morales íntegros y rescatar la idea kantiana del ciudadano imperfecto.

${ }^{53}$ Con respecto a la condena moral de la hipocresía no está de más recordar al marqués de Condorcet (op. cit., pág. 216): «No hagáis nada que un hombre sensato pueda tomar como prueba de que creéis lo que no creéis. La línea que separa la prudencia de la hipocresía es aquí muy fácil de traspasar, pero es mejor quedarse más allá y ser imprudente que no hipócrita». Con respecto a los costes sociales de la hipocresía, cfr. el sumamente sugerente libro de Michael Baurmann, Der Markt der Tagend, Tubinga: J. V. B. Mohr 1996 (versión castellana de Ernesto Garzón Valdés: El mercado de la virtud, Barcelona: Gedisa 1998).

DOXA 21-I (1998) 